\title{
EDITORIAL
}

\section{IMPLEMENTING FRAILTY INTO CLINICAL PRACTICE: WE CANNOT WAIT}

\author{
B. VELLAS ${ }^{1}$, P. CESTAC ${ }^{2}$, J.E. MORLEY ${ }^{3}$
}

1. I.A.G.G. President, Chair Gerontopole, Univeristy of Toulouse, France; 2. Pôle Pharmacie CHU Toulouse and INSERM U1027; 3. Dammert Professor of Medicine and Director, Division of Geriatric Medicine, Saint Louis University School of Medicine, St. Louis, Missouri USA

Geriatric medicine was implemented in many countries in the 1980s due to the discharge of many older adults with multiple pathologies, cognitive impairment and severe disabilities to emergency departments. In fact, at that time nobody was capable or wanted to care about these older adults with severe disabilities. For these reasons, most of the departments of geriatrics were created at that time. Most were based in sub-acute and long term care to take care of these patients. Since then, geriatric medicine has grown in many countries and now there are acute care units, day hospitals, mobile teams and memory clinics worldwide. However, today in most of these centers geriatric physicians are dealing with patients with already severe disabilities at a stage which is often not reversible. Almost $95 \%$ of the geriatric force is involved in care for already dependent older adults. We need, of course, to continue to take care of these individuals with severe disabilities, but moreover, we need to take care of the pre-frail and frail older adults. It is an absolute necessity if we want to prevent rapid disability in our aging population, and if we want to anticipate it to promote more efficient care.

Pre-frail and frail older adults are those following the Fried criteria who have a sedentary life, an involuntary weight loss, low physical activity, exhaustion, low strength (1-7). If they have one of the Fried criteria, they are pre-frail; if they have 3 or more, they are frail (1). Frail older adults are more likely to become dependent, but today they are not really taken into consideration by our health care systems. We need, in collaboration with the family physicians, to take up this challenge. To do it we need a targeted, strong and sustained intervention.

- Targeting the pre-frail and frail older adults. To do this we need a simple tool to be used by family practitioner and other health professionals to screen those at risk of being frail. The IANA tool (a simple 5 questions) recently validated by Morley et al. is a good example (4). Another example is the tool used in the Gerontopole Frailty Clinics. It is useful to keep the subjective assessment of the physician if we want to keep him/her involved in the interventional process.

- Important Intervention: To have a real impact the intervention must be strong. To do this a complete geriatric assessment of the pre-frail and frail patients is necessary to be able to diagnose some age-related disease at a prodromal stage, where it is still possible to cure the patient: e.g., early stage of macular degeneration, glaucoma, hearing impairment, mild cognitive impairment, sarcopenia (8.9) or loss of mobility. It is also an opportunity to have this population benefit from new drug trials in prodromal Alzheimer's disease in an early stage of sarcopenia for example. The evaluation must use specific tools to do most accurate diagnosis of potential age related diseases. This assessment must include also social, health, economic and psychosocial assessment, as well as the evaluation of the deficit accumulation (10).

- A sustained Intervention. Because the aging of this population will still increase, we need to have long-term and sustained intervention. Physical exercise, cognitive exercise, nutrition intervention, social services will be needed in association of the detection and treatment of age related diseases. A recent study showed that even in older frail persons with hip fracture, a sustained resistance exercise program for one year can improve outcomes (11). More standardization of these multi-domain interventions is an important domain for further research. We need to find a compromise between very strong interventions which will be accepted by few frail older adults and too light interventions usually not strong enough to have a real impact.

- The I.A.G.G. (International Association of Gerontology and Geriatrics), http://www.iagg.info/ and the G.A.R.N. (IAGG Global Aging Research Network) http://garnnetwork.org/index.php have already taken and will take further initiative in this domain. They have pointed out the need to concentrate on aging-in-place to prevent premature nursing home placement (12). We really need to implement pre-frail and frailty in usual geriatric care worldwide.

If we are able to recognize and treat frailty in our clinical practice, it will be a new area for geriatric medicine. At this time, we will be able to develop high level clinical research on biomarkers, imaging and new treatment approaches. Multidomain or multimodal intervention will be most probably necessary. At the same time, some actions have to be implemented to prevent iatrogenic hospitalization if these frail older adults have to be hospitalized (13). This move of geriatric medicine in the pre-frail and frail will be cost effective and can give a new rebound for geriatrics, as recommended in a recent European intiaitves $(14,15)$. 


\section{IMPLEMENTING FRAILTY INTO CLINICAL PRACTICE: WE CANNOT WAIT}

\section{References}

1. Fried LP, Tangen CM, Walston J, Newman AB, Hirsch C, Gottdiener J, Seeman T, Tracy R, Kop WJ, Burke G, McBurnie MA; Cardiovascular Health Study Collaborative Research Group. Frailty in older adults: Evidence for a phenotype. J Gerontol A Biol Sci Med Sci. 2001;56:M146-M156.

2. Abellan van Kan G, Rolland Y, Houles M, Gillette-Guyonnet S, Soto M, Vellas B. The assessment of frailty in older adults. Clin Geriatr Med 2010;26:275-286. PubMed PMID: 20497846.

3. Abellan van Kan G, Rolland Y, Andrieu S, Bauer J, Beauchet O, Bonnefoy M, Cesari M, Donini LM, Gillette Guyonnet S, Inzitari M, Nourhashemi F, Onder G, Ritz P, Salva A, Visser M, Vellas B; International Academy on Nutrition and Aging (IANA) Task Force. Gait speed at usual pace as a predictor of adverse outcomes in community-dwelling older people. J Nutr Health Aging 2009;13:881-889.

4. Morley JE, Malmstrom TK, Miller DK. A simple frailty questionnaire (FRAIL) predicts outcomes in middle aged African Americans. J Nutr Health Aging, in press.

5. Abellan van Kan G, Rolland YM, Morley JE, Vellas B. Frailty: Toward a clinical definition. J Am Med Dir Assoc 2008;9:71-72.

6. Abellan van Kan G, Rolland Y, Bergman H, Morley JE, Kritchevsky SB, Vellas B. The I.A.N.A. Task Force on frailty assessment of older people in clinical practice. J Nutr Health Aging 2008;12:29-37.

7. Nourhashemi F, Andrieu S, Gillette-Guyonnet S, Vellas B, Albarede JL, Grandjean H. Instrumental activities of daily living as a potential marker of frailty: A study of 7364 community-dwelling elderly women (the EPIDOS study). J Gerontol A Biol Sci Med Sci 2001;56:M448-M453.

8. Chumlea WC, Cesari M, Evans WJ, Ferrucci L, Fielding RA, Pahor M, Studensky S, Vellas B; International Working Group on Sarcopenia Task Force Members. Sarcopenia: Designing phase IIB trials. J Nutr Health Aging 2011;15:450-455.

9. Fielding RA, Vellas B, Evans WJ, Bhasin S, Morley JE, Newman AB, Abellan van Kan G, Andrieu S, Bauer J, Breuille D, Cederholm T, Chandler J, De Meynard C,
Donini L, Harris T, Kannt A, Keime Guibert F, Onder G, Papanicolaou D, Rolland Y, Rooks D, Sieber C, Souhami E, Verlaan S, Bamboni M; International Working Group on Sarcopenia. Sarcopenia: An undiagnosed condition in older adults. Current consensus definition: Prevalence, Etiology, and consequences. J Am Med Dir Assoc 2011;12:249-256.

10. Singh NA, Quine S, Clemson LM, Williasm EJ, Williamson DA, Stavrinos TM, Grady JN, Perry TJ, Lloyd BD, Smith EU, Singh MA. Effects of high-intensity progressive resistance training and targeted multidisciplinary treatment of frailty on mortality and nursing home admissions after hip fracture: A randomized controlled trial. J Am Med Dir Assoc 2012;13:24-30.

11. Tolson D, Rolland Y, Andrieu S, Aquino JP, Beard J, Benetos A, Berrut G, CollPlanas L, Dong B, Forette F, Franco A, Franzoni S, Salva A, Swagerty D, Trabucchi M, Vellas B, Volicer L, Morley JE; The International Association of Gerontology and Geriatrics/World Health Organization/Society Française de Gérontologie et de Gériatrie Task Force. International Association of Gerontology and Geriatrics: A global agenda for clinical research and quality of care in nursing homes. J Am Med Dir Assoc 2011;12:184-189.

12. Rockwood K, Mitnitski A. How might deficit accumulation give rise to frailty? J Frailty Aging 2012;1:8-12

13. Lafont C, Gérard S, Voisin T, Pahor M, Vellas B; Members of I.A.G.G./A.M.P.A. Task Force. Reducing "iatrogenic disability" in the hospitalized frail elderly. J Nutr Health Aging 2011;15:645-660.

14. Rodriguez-Mañas L, Féart C, Mann G, Viña J, Chatterji S, Chodzko-Zajko W, Gonzalez-Colaço Harmand M, Bergman H, Carcaillon L, Nicholson C, Scuteri A, Sinclair A, Pelaez M, Van der Cammen T, Beland F, Bickenbach J, Delamarche P, Ferrucci L, Fried LP, Gutierrez-Robledo LM, Rockwood K, Rodriguez Artalejo F, Serviddio G, Vega E; on behalf of the FOD-CC group (Appendix 1). Search for an Operational definition of frailty: A Delphi method based consensus statement. The Frailty Operative Definition-Consensus conference project. J Gerontol A Biol Sci Med Sci 2012;67.

15. Cesari M. Frailty and Aging J Frailty Aging 2012;1(1):3-6 